\title{
The Temperature and Pressure Dependencies of Propagation Characteris- tics for Premixed Laminar Ethanol-Air Flames
}

\author{
S. Y. Liao*,a, D. L. Zhong, ${ }^{*,}$, C. Yang ${ }^{\mathrm{b}}$, X. B. Pan ${ }^{\mathrm{a}}$, C. Yuan ${ }^{\mathrm{a}}$ and Q. Cheng ${ }^{\mathrm{a}}$ \\ ${ }^{a}$ Department of Power Engineering, College of Chongqing Communication, Chongqing 400035, P.R China \\ ${ }^{b}$ Key Laboratory of Low-grade Energy Utilization Technologies and Systems of Ministry of Education, and School of \\ Thermal Engineering, Chongqing University, Chongqing 400044, P.R China
}

\begin{abstract}
Laminar burning velocity is strongly dependent on mixture characteristics, e.g. initial temperature, pressure and equivalence ratio. In this work, spherically expanding laminar premixed flames, freely propagating from a spark ignition source in initially quiescent ethanol-air mixtures, have been imaged and then the laminar burning velocities were obtained at initial temperatures of $358 \mathrm{~K}$ to $500 \mathrm{~K}$, pressure of 0.1 to $0.2 \mathrm{MPa}$ and equivalence ratio of 0.7 to 1.4 . The measured results and literature data on ethanol laminar burning velocities were accumulated, to analyze the effects of initial temperature and pressure on the propagation characteristics of laminar ethanol-air flames. $A$ correlation in the form of

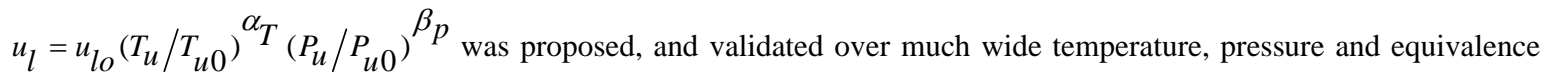
ratio ranges. The global activation temperatures were determined in terms of the laminar burning mass flux for ethanol-air flames. And the Zel'dovich numbers were estimated as well. The dependencies of global activation temperature and Zel'dovich number on initial mixture pressure, temperature and equivalence ratio were explored. Additionally, an alternative correlation of laminar burning velocities, from the view of theoretical arguments, was proposed on the basis of the determined ethanol-air laminar mass burning flux. Good agreements were obtained in its comparison with the literature data.
\end{abstract}

Keywords: Ethanol, laminar burning velocity, burning mass flux, Zel’dovich numbers, activation temperature.

\section{INTRODUCTION}

In response to the environmental problems related to oil consumption and the associated emissions of $\mathrm{CO}_{2}$ and other pollutants, many politicians, researchers and others advocated for the use of alternative fuels to replace conventional fossil fuels. Ethanol is a renewable energy since it can be commonly produced from bio-mass [1], such as softwoods, sugar cane and maize. And it has been identified as offering an attractive potential to improve air quality when used to replace conventional gasoline or diesel in engines because of its good anti-knock characteristics and the reduction of CO and unburned hydrocarbon (HC) emissions [2]. Considering its excellent performances in engine and renewable feature, ethanol is being regarded as one of the most promising alternative fuels for engines.

A key characteristic of a fuel is its laminar burning velocity, which is fundamentally important in regard to predicting its performance in combustion system, as well as in regard to design of engine. The studies relevant to its determination have been extensively implemented in the last fifty years. The tested fuels have covered most of hydrocarbon fuels,

\footnotetext{
*Address correspondence to these authors at the Department of Power Engineering, College of Chongqing Communication, Chongqing 400035, P.R China; Tel/Fax: +86-23-65350879; E-mail: shyliao@yahoo.com.cn; Key Laboratory of Low-grade Energy Utilization Technologies and Systems of Ministry of Education, and School of Thermal Engineering, Chongqing University, Chongqing 400044, P.R China; Tel/Fax: +86-23-65102473; E-mail: zhongdl@cqu.edu.cn
}

e.g. methane [3, 4] hydrogen [5], iso-octane [6], tert-butanol [7] etc. The first systematic measurement for laminar ethanol-air flames was initiated by Gülder [8] in 1982. He conducted an experiment for premixed ethanol-air mixtures in a closed combustion bomb, and obtained the laminar burning velocities in the range of 0.1-0.8 MPa pressures, 300-500K temperatures and equivalence ratios from 0.7 to 1.4. In his study, the laminar burning velocities were obtained from the measured flame growth rate by using six ionization probes installed in the combustion bomb, and the effect of stretch, which was imposed on the flame, have been ignored. Hereafter, Egolfopoulos et al. [9] implemented a counterflow ethanol flames measurement at atmospheric pressure in 1992, and determined the laminar burning velocities between 363 and $453 \mathrm{~K}$.

The bursting attentions on ethanol laminar flames occurred in the beginning of the $21^{\text {st }}$ century, because of the approved attraction of ethanol to improve engine performances. Holley et al. [10] conducted an experimental measurement and chemical kinetics computation to determine this fundamental parameter for premixed ethanol-air laminar flame in 2004. Subsequently, Farrell [11], Liao [12], Bradley [13], Konnov [14] and Eisazadeh-Far [15] with their coworkers, made experiments at the extended mixture temperatures, pressures or equivalence ratios ranges, and reported some literature data for gaseous ethanol mixtures in air. However, the obtained results still presented somewhat apparent scatterings. 
As we know, laminar burning velocity is a strongly dependent parameter of mixture features, e.g. initial temperature, pressure and mixture equivalence ratio. And generally, this fundamental parameter is determined at standard condition, for example, atmospheric pressure and initial temperature of $298 \mathrm{~K}$, or relatively low temperature and pressure, primarily owing to some difficulties in experimental setups and measurements . However, in most practical applications, initial pressure and temperature of the mixture are often higher than the standard values. Therefore, it is very important to quantify the effects of pressure and temperature on these fundamental parameters [14]. Shown in Table $\mathbf{1}$ is an overview on the temperature and pressure dependencies of laminar burning velocities for ethanol-air flames. We note that, Liao et al. [12] and Konnov et al. [14] proposed the correlations in the form of $u_{l}=u_{l o}\left(T_{u} / T_{u 0}\right)^{\alpha_{T}}$. Their particular attentions were paid on the effect of initial temperature on laminar burning velocities. Gülder [8] gave his empirical formula in the form of $u_{l}=u_{l o}\left(T_{u} / T_{u 0}\right)^{\alpha_{T}}\left(P_{u} / P_{u 0}\right)^{\beta_{p}}$ and validated the temperature and pressure power exponent coefficients over the range of initial temperatures from 300 to $500 \mathrm{~K}$ at the pressure of $0.8 \mathrm{MPa}$. In his study, $\alpha_{T}$ was a constant of 1.75 , and a piecewise function was obtained to describe the power exponent $\beta_{p}$ against mixture equivalence ratio. Hereafter, Bradley et al. [13] made their experimental measurements from 0.1 up to $1.4 \mathrm{MPa}$, and Eisazadeh-Far et al. [15] extended the measured temperatures up to $650 \mathrm{~K}$. They summarized some empirical correlations to formulize the effects of pressure and temperature on laminar burning velocities as well. Generally speaking, all empirical expressions mentioned above were valuable for most of practical applications. However, their major disadvantages were their limited validation ranges for initial temperatures, pressures, and equivalence ratios. For instance, the pressure dependence have not been investigated by Liao et al. [12] and Konnov et al. [14]; the equations proposed by Bradley et al. [13] and Eisazadeh-Far et al. [15] were only validated within equivalence ratios from 0.8 to 1.2 ; the study of Gülder[8] showed apparent scatterings against the latest literature data. Moreover, others important propagation characteristics for laminar ethanol-air flames, such as the global activation flame temperatures and Zel'dovich numbers, have still scarcely been studied. It is therefore necessary to make a comprehensive study on the laminar ethanol-air flames dependencies, over much wider temperatures, pressures, and equivalence ratios ranges, for much better understanding, and modeling combustion process of ethanol.

The experimental method used herein was the expanding flame imaging and processing technique, which have been well-established to deduce flame speed, flame stretch, as well as laminar burning velocity from the recorded history of flame kernel development. The major objective of this paper, therefore, was to provide some improved expressions for laminar ethanol-air flames, as well as to study their temperature and pressure dependencies. The validations were implemented for these proposed empirical equations over much wider mixture conditions, through the comparison of present measurement with the latest literature data. Furthermore, on the basis of the asymptotic theory of flame structure, the expressions for global activation flame temperature, Zel'dovich numbers have been deduced, and their dependencies on mixture parameters were explored as well.

\section{EXPERIMENTAL SETUP AND DATA PROCESSING}

The spherically expanding flame method in a constant volume combustion bomb have been extensively used to measure laminar burning velocities of gaseous and liquid fuels. Detailed description of this method and the associated experimental uncertainties could be found elsewhere [12]. Herein, some important features were outlined in the following. In the present experiment, $a$ stainless steel bomb with an inside size of 108x108x135mm was employed. Two sides of the bomb were transparent to make the inside observable and provide the optical access for flame imaging. Two electric heaters were mounted at the bomb wall to preheat the gas and a closed-loop controlling system have been used to ensure the gas temperature at a desired value. The experimental procedures involved five steps primarily. Firstly, the bomb

Table 1. Summery of the Investigation on Laminar Burning Velocities for Ethanol-air Flames

\begin{tabular}{|c|c|c|c|c|c|c|c|}
\hline Authors & $\alpha_{\mathrm{T}}{ }^{\mathrm{a}}$ & $\beta_{P}{ }^{b}$ & $\begin{array}{c}\text { Temperature } \\
\text { (K) }\end{array}$ & Pressure (MPa) & Equivalence Ratio $(\phi)^{\mathrm{c}}$ & $\begin{array}{c}\text { Experimental Tech- } \\
\text { nique }\end{array}$ & Year \\
\hline Gülder & $\mathrm{O}$ & $\mathrm{O}$ & $300-500$ & $0.1-0.8$ & $0.7-1.4$ & combustion bomb & 1982 \\
\hline Egolfopoulos et al. & $\mathrm{X}$ & $\mathrm{X}$ & $363-453$ & 0.1 & $0.6-1.8$ & counter-flow flame & 1992 \\
\hline Farrell et al. & $\mathrm{X}$ & $\mathrm{X}$ & 450 & 0.3 & $0.55-1.3$ & combustion bomb & 2004 \\
\hline Liao et al. & $\mathrm{O}$ & $X^{d}$ & $358-480$ & 0.1 & $0.7-1.4$ & combustion bomb & 2007 \\
\hline Bradley et al. & $\mathrm{O}$ & $\mathrm{O}$ & $300-393$ & $0.1-1.4$ & $0.8-1.2$ & combustion bomb & 2009 \\
\hline Konnov et al. & $\mathrm{O}$ & $\mathrm{X}$ & $298-358$ & 0.1 & $0.65-1.55$ & heat flux method & 2011 \\
\hline Eisazadeh-Far et al. & $\mathrm{O}$ & $\mathrm{O}$ & $300-650$ & $0.1-0.5$ & $0.8-1.1$ & cylindrical vessel & 2011 \\
\hline
\end{tabular}

a, b letters of ' $O$ ' and ' $\mathrm{X}$ ' indicate the parameters of $\alpha_{\mathrm{T}}$ and $\beta_{\mathrm{p}}$ are available or not respectively, where $\alpha_{\mathrm{T}}$ and $\beta_{\mathrm{p}}$ are the parameters in Equation 7 .

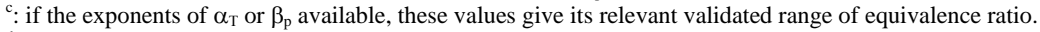

d: the exponent of $\beta_{\mathrm{p}}$ is reproduced from Gülder [8]. 
would be preheated to a value above the desired temperature and then left to cool. Following, the combustion bomb was evacuated and flushed with air to remove residuals from previous experiment and evacuated again. Thirdly, the liquid fuel was injected into the combustion chamber using a Gas Tight syringe, at a pressure close to vacuum. Subsequently, dried air was introduced into chamber and the perforated plate started to move manually, to enhance the motion of fuel in air for the homogenous distributions of mixture density and temperature. In the present experiment, as all measured temperatures were beyond the boiling point of ethanol, the injected liquid ethanol could be evaporated rapidly at a pressure close to vacuum. Finally, the ignition occurred when the gas temperature attained to the desired temperature and the motion of perforated plate have been suspended for at least five minutes, to ensure combustible mixture at quiescent condition. Meanwhile, the history of the shape and size of the developing flame kernel was recorded synchronously by a REDLAKE HG-100K high-speed CCD camera, operating at 5000 pictures per second with a schlieren optical system.

The laminar burning velocity could be deduced from the well-established expanding flames method as described in some literatures [12]. Given in follows was a sketch about this method. Herein, the stretched flame speed, $S_{n}$, is derived from the flame radius versus the elapsed time $t$ as,

$S_{n}=\frac{d r_{u}}{d t}$

where flame size.$r_{u}$. is determined from the schlieren flame area directly. by,

And the flame stretch, $\alpha$, of a flame front is then given

$\alpha=\frac{1}{A} \frac{d A}{d t}$

where $A$ indicates the flame front area. In the case of outwardly propagating spherical flame, it can be determined as,

$\alpha=\frac{1}{A} \frac{d A}{d t}=\frac{2}{r_{u}} \frac{d r_{u}}{d t}=\frac{2}{r_{u}} S_{n}$

The unstretched flame speed, $S_{l}$, is obtained from ,

$S_{l}-S_{n}=L_{b} \alpha$

Thereby, the unstretched laminar burning velocity, $u_{l}$, yields as,

$u_{l}=\rho_{b} S_{l} / \rho_{u}$

Where $\rho_{u}$ is the density of the unburned and $\rho_{b}$ that of the burned gas, which can be determined from quasidimensional two-zone combustion model [16]. The standard error of estimation can be found in [6].

\section{RESULTS AND DISCUSSIONS}

Laminar burning velocities of ethanol-air flames were measured using the spherically expanding method within the ranges of $358-500 \mathrm{~K}$, equivalence ratios from 0.7 to 1.4 and at pressure of 0.1 and $0.2 \mathrm{MPa}$. As mentioned above, following a series of procedures about flame processing, the values of flame area, flame radius, and subsequently, flame speed, flame stretch rate, the density of burned and unburned mixture, and laminar burning velocities of ethanol flames could be derived methodically. Plotted in Fig. (1) were the measured laminar burning velocities for ethanol-air flame at 358K and atmospheric pressure, against mixture equivalence ratio. This figure plotted some literature data for comparison as well. Generally speaking, acceptable agreements have been achieved, and especially for lean and stoichiometric fuel-air mixtures. Compared to the data of Bradley et al. [13] (2009), Konnov et al. [14] (2011) and Eisazadeh-Far et al. [15] (2011), it was obvious that our measurements were comparable, and the best agreements appeared in the comparison with the experiment made by Bradley et al. Compared to the results of Bradley et al. and Konnov et al., some apparent deviations were also displayed for flames of equivalence ratio bigger than 1.3. It is possible due to the small dimensions of the vessel used. However, these discrepancies were within an acceptable zone against those measured by Gülder and Egolfopoulos et al. We can see that, for ethanol-air flame, at normal pressure of $0.1 \mathrm{MPa}$ and temperature of $358 \mathrm{~K}$, the maximum burning velocity was approximately between $58 \mathrm{~cm} / \mathrm{s}$ and $61 \mathrm{~cm} / \mathrm{s}$. And on the basis of all the available literature data, the unstretched laminar burning velocities could be formulized as a function of equivalence ratio by means of the least-squares method, as

$u_{10} /\left(\mathrm{cm}_{\mathrm{s}} \mathrm{s}^{-1}\right)=-175.02 \phi^{2}+391.1 \phi-162.5$

Where the subscript ' 0 ' indicated the reference conditions, i.e., $358 \mathrm{~K}$ and $0.1 \mathrm{MPa}$ in this work. As large amounts of data have been introduced to the empirical equation development, we can obviously find that, the present equation showed a better agreement with all measured data, compared to that previous version, $u_{10}=-207.07 \phi^{2}+450.1 \phi-189.71$ [11], as plotted in Fig. (1) as well. The maximum burning velocity of Eq. 6 was about at the equivalence ratio of 1.07 , corresponding to the measured value of $58.1 \mathrm{~cm} / \mathrm{s}$. In Fig. (1), a highlighted zone was illustrated to show the $\pm 5 \%$ deviations of Eq.6. Note that, most of experimental measurements appeared within this zone. And only a spot of points were exceptions, e.g. the measurements of Bradley et al. Konnov et al. and the present experiment at equivalence ratio of 0.9 , and our measurement for mixture of 1.4. Moreover, a comprehensive comparison have been conducted between the present measured laminar burning velocities and other literature data for mixtures at $358 \mathrm{~K}$, and $453 \mathrm{~K}$ at 0.2 $\mathrm{MPa}$, as presented in Fig. (2) and Fig. (3) respectively. We note that, the present experimental results were fully comparable with those made by Bradley et al. while the predictions of Eisazadeh-Far et al, [15] were obviously bigger than the measured values, in which apparent discrepancies have been observed in the comparison between the empirical prediction and the experimental data, when mixture equivalence ratios were in a higher range. This was due to the empirical solution of Eisazadeh-Far et al, was validated only within a comparatively narrow equivalence ratio range. 
As we know, laminar burning velocity is a strongly dependent function of mixture characteristics, such as initial temperature, pressure and mixture equivalence ratio. More often, these dependencies could be generally expressed as a simple power law correlations of nondimensional temperature $\left(T_{u} / T_{u 0}\right)$ and nondimensional pressure $\left(P_{u} / P_{u 0}\right)$, at the datum conditions, as

$u_{l}=u_{l o}\left(T_{u} / T_{u 0}\right)^{\alpha_{T}}\left(P_{u} / P_{u o}\right)^{\beta_{P}}$

Where $\alpha_{T}$ and $\beta_{P}$ were the temperature and pressure exponents respectively.
Note that, Eq.7 could also be rewritten as,

$$
\log \left(u_{l} / u_{l o}\right)=\alpha_{T} \log \left(T_{u} / T_{u 0}\right)+\beta_{P} \log \left(P_{u} / P_{\text {uо }}\right)
$$

Obviously, it is not hard to determine the parameters of $\alpha_{T}$ and $\beta_{P}$, by means of the least-squares analyses of $\log \left(u_{l} / u_{l o}\right) \quad$ vs. $\log \left(T_{u} / T_{u 0}\right) \quad$ and $\log \left(u_{l} / u_{l o}\right) \quad$ vs. $\log \left(P_{u} / P_{\text {ио }}\right)$ respectively. Shown in Fig. (4) were two selections about the determinations of $\alpha_{T}$ and $\beta_{P}$. We note that, the linear relationship was much stronger in the plots of $\log \left(u_{l} / u_{l o}\right)$ vs. $\log \left(T_{u} / T_{u 0}\right)$ than in that of $\log \left(u_{l} / u_{l o}\right)$ vs.

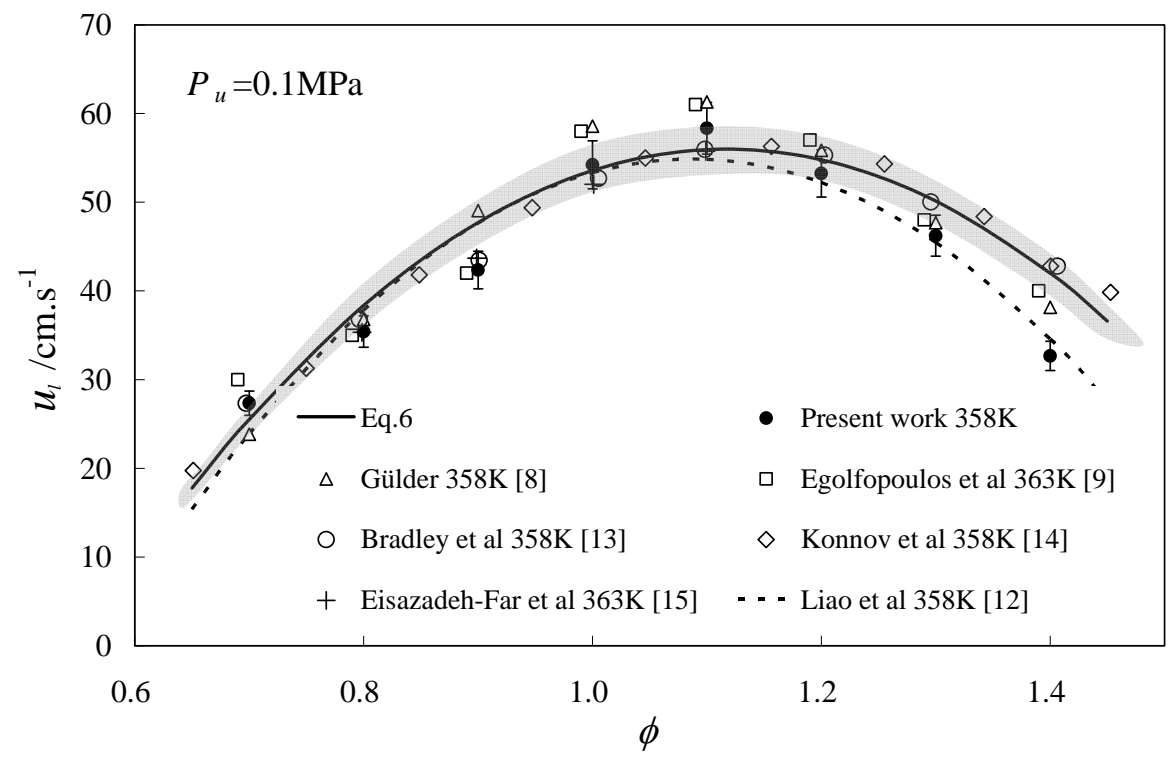

Fig. (1). Laminar burning velocities for ethanol-air flames at $358 \mathrm{~K}$ and $0.1 \mathrm{MPa}$, where experimental values shown by symbols, the solid curve obtained from Eq.6, the dotted curve obtained from computation of Liao et al. [12]. The shaded area indicates the zone of $\pm 5 \%$ deviations for Eq.6 predictions (some experimental symbols have been displaced slightly on the $\mathrm{x}$-axis to improve clarity).

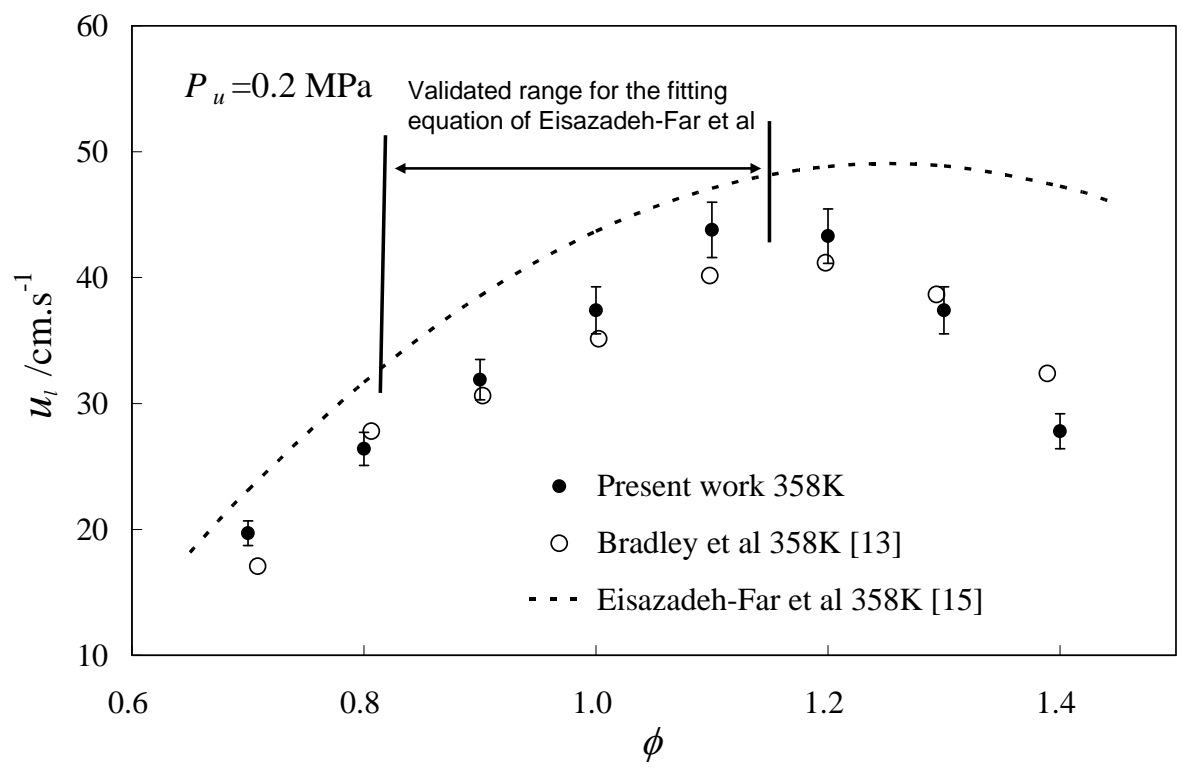

Fig. (2). Laminar burning velocities for ethanol-air flames at $358 \mathrm{~K}$ and $0.2 \mathrm{MPa}$, where experimental values shown by symbols, and the dashed curve is obtained from the fitting equation of Eisazadeh-Far et al. [15] (which was validated within the equivalence ratio ranging from 0.8 to 1.1 , and some experimental symbols have been displaced slightly on the $\mathrm{x}$-axis to improve clarity). 


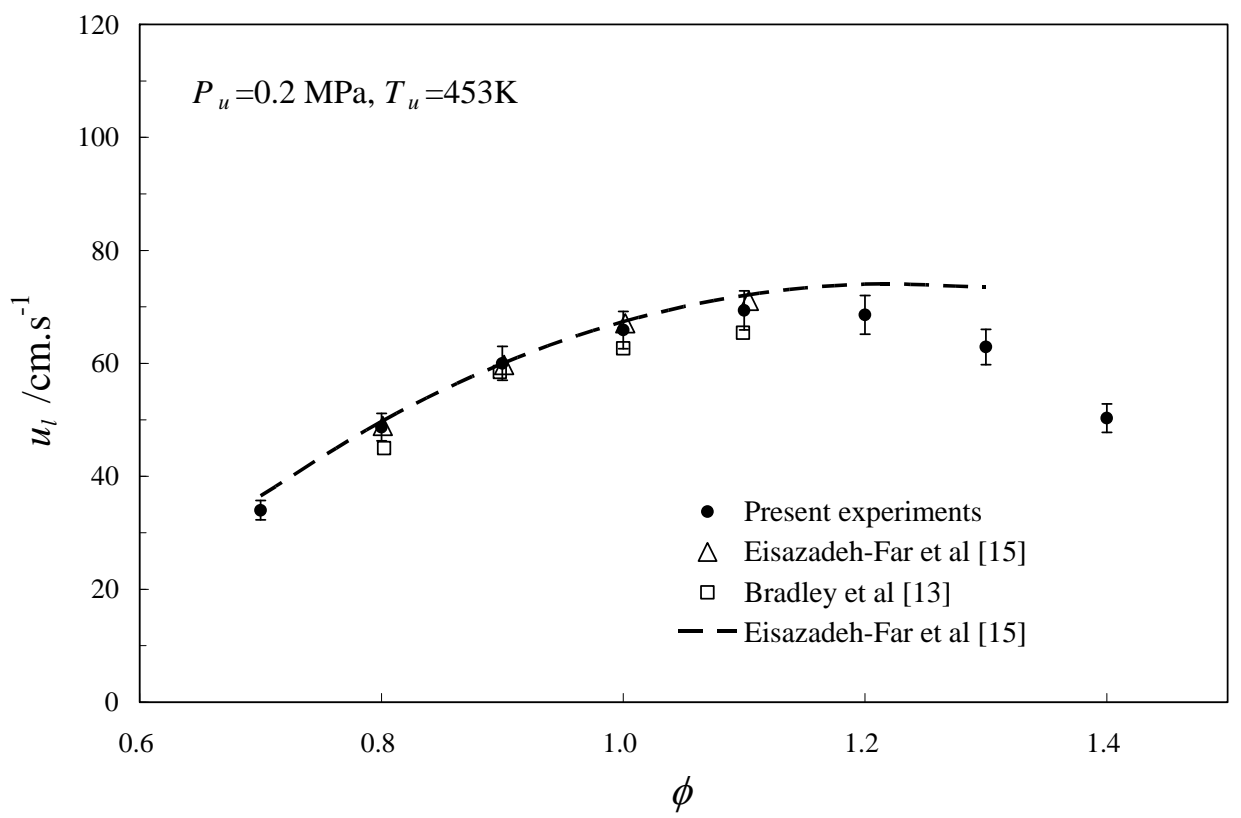

Fig. (3). Laminar burning velocities for ethanol-air flames at $453 \mathrm{~K}$ and $0.2 \mathrm{MPa}$. Experimental values shown by symbols. Computed values shown by dotted and dashed curves respectively. (Some experimental symbols have been displaced slightly on the $\mathrm{x}$-axis to improve clarity).

$\log \left(P_{u} / P_{u о}\right)$. In which, most experimental measurements were scattered around the fitted line closely. Thereby it is easy to get the value of $\alpha_{T}$, as shown in Fig. (4A). However, more obvious scatterings have been observed in the plots of $\log \left(u_{l} / u_{l o}\right)$ vs. $\log \left(P_{u} / P_{u o}\right)$. Fig. (4B) also revealed that the present measurements have shown a comparable slope of $\log \left(u_{l} / u_{l o}\right)$ against $\log \left(P_{u} / P_{u o}\right)$ with that of Bradley et al. [13]. Actually, it is very difficult to find some physical meanings to this phenomenon, but similar research facilities and similar data procedures were the possible reasons. As these reasons could also be used to analyze the clustering behaviors for measurements of Eisazadeh-Far et al. [15] and Gülder [8]. In their studies, the laminar burning velocities were commonly derived from pressure rise histories. The experimental method was apparently different from the flame processing technique used by Bradley et al. [13] and the authors. Thereby, the pressure exponent $\beta_{P}$ was also determined from the linear fitting among the measurements of present experiment and those of Bradley et al. Whilst, because the initial temperature showed much stronger influence on flame propagation than pressure $\left(\alpha_{T}>>\beta_{P}\right)$, weak variation in value of $\alpha_{T}$ have not brought a comparable statistical result as that of $\beta_{P}$. Fig. (5) showed the variations of $\alpha_{T}$ and $\beta_{P}$, against mixture equivalence ratio. On these bases, two generalized correlations have been summarized to quantify their dependencies on the equivalence ratio, as given in Eq.9 and Eq.10.

$$
\begin{aligned}
& \alpha_{T}=1.4738 \phi^{2}-3.5786 \phi+3.8944 \\
& \beta_{P}=-0.4094 \phi^{2}+1.0147 \phi-0.9181
\end{aligned}
$$

In Fig. (5), it is clear that $\alpha_{T}$ obtained by Bradley et al., Eisazadeh-Far et al., and Gülder showed stronger influence on the temperature exponent than those of Konnov et al. The reason for it is probably the lower temperature range of the experiments of Konnov et al. While for $\beta_{P}$, the variation of present values was nearly same as that of Bradley et al. Fig. (5) also showed two \pm 0.3 and \pm 0.15 deviation zones for $\alpha_{T}$ and $\beta_{\mathrm{p}}$ respectively. In general, all differences were not great. And the relative deviations of temperature exponent $\alpha_{T}$ were obviously smaller than those in $\beta_{P}$, although the temperature have presented greater dependence than pressure in the burning velocity of ethanol.

Eqs.7 through 10, have given a set of empirical expressions for the laminar burning velocities of ethanol-air mixture. In order to validate these empirical formulas, it is informative to let them make further comparisons with large amounts of literature data. Presented in Fig. (6) and Fig. (7) were some selective results, and good agreements have yielded among them. From these validations, we could confirm that, the proposed formulas could predict ethanol-air laminar burning velocities well, and their applicable ranges have been extended to some extent. For instance, their validated temperature range was from $300 \mathrm{~K}$ to $600 \mathrm{~K}$ and pressure from 0.1 to $1.4 \mathrm{MPa}$. certainly, one of the most important reasons was that the literature data introduced into the development of empirical equations have covered an extensive temperature and pressure ranges.

Theoretical analyses for stretched flames [17, 18] have reported that, the global activation energy $E$ for the unstretched planar flame propagation could be determined on the basis of laminar burning velocities. Peters and Williams [19] have derived an asymptotic structure of the flame that introduced the inner layer temperature $T^{0}$ in the fuel consumption, and claimed that an apparent expression existed 


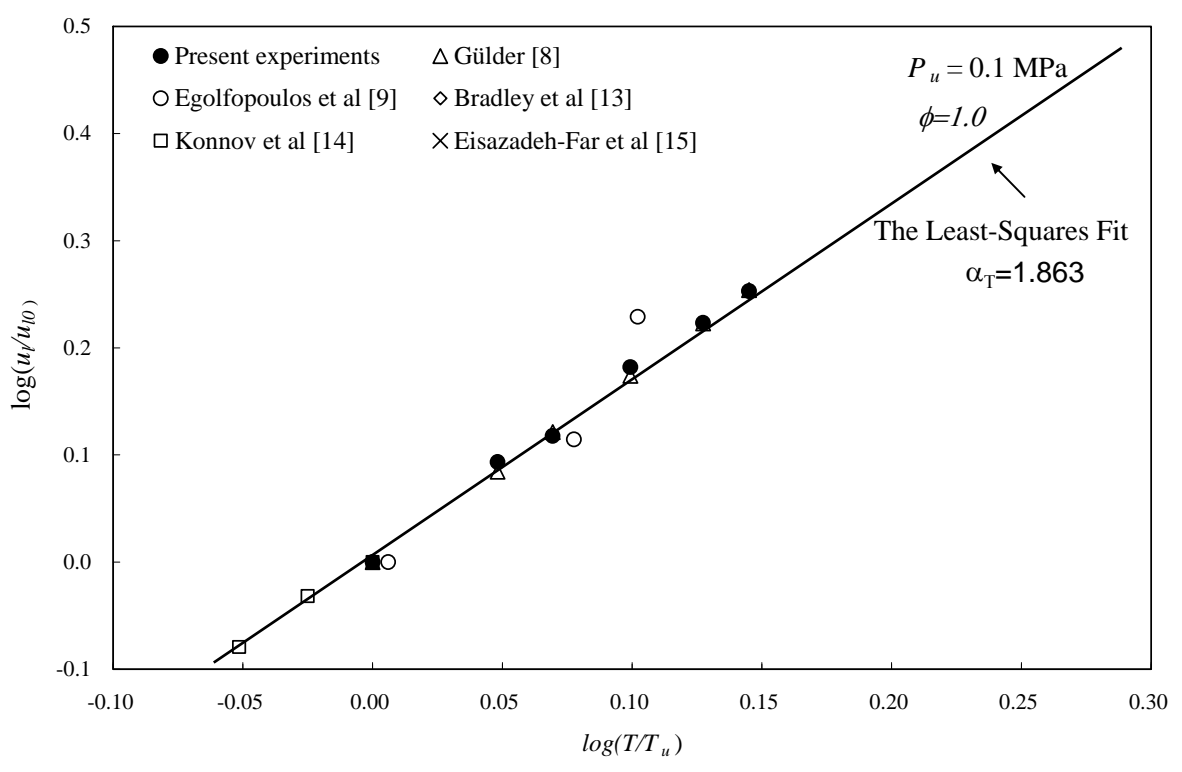

A: $\log \left(u_{l} / u_{l o}\right)$ vs. $\log \left(T_{u} / T_{u 0}\right)$

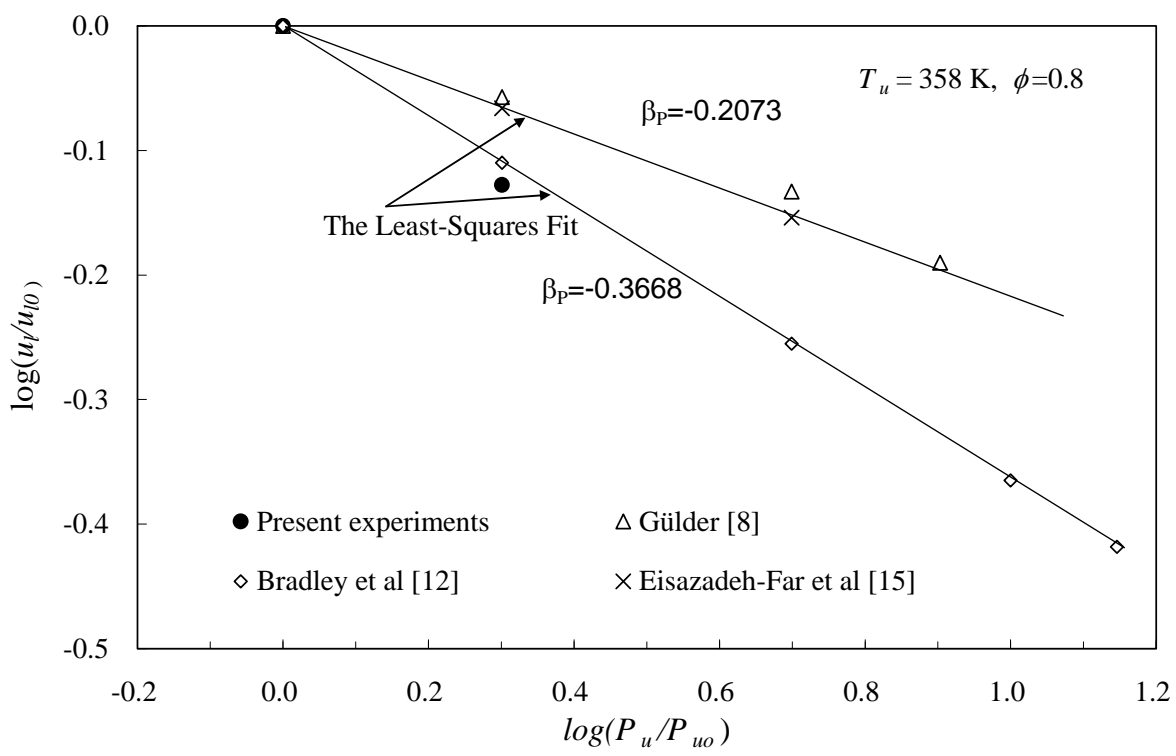

B: $\log \left(u_{l} / u_{l o}\right)$ vs. $\log \left(P_{u} / P_{u o}\right)$

Fig. (4). Determinations of temperature and pressure exponents of Eq.7.

within the activation temperature $E / R$ and mass flux $\left(\rho_{u} u_{l}\right)$, given as,

$$
\frac{E}{R}=2 T_{b}^{2} \frac{d\left[\ln \left(\rho_{u} u_{l}\right)\right] /\left(\mathrm{g} \cdot \mathrm{cm}^{2} \cdot \mathrm{s}^{-1}\right)}{d T_{b}}
$$

where $R$ is the universal gas constant. Obviously, Eq.11 can also be rewritten as an alternative form,

$$
\frac{E}{R}=-\frac{d 2\left[\ln \left(\rho_{u} u_{l}\right)\right] /\left(g \cdot \mathrm{cm}^{2} \cdot \mathrm{s}^{-1}\right)}{d\left(1 / T_{b}\right)}
$$

which indicated that the activation temperature $E / R$ can be derived from the linear plot of $2 \ln \left(\rho_{u} u_{l}\right)$ against $1 / T_{b}$ directly. That is to say, it is not hard to obtain the activation temperature $E / R$ for a specific laminar planar flame when its laminar burning velocities were known. Shown in Fig. (8) were some plots of $2 \ln \left(\rho_{u} u_{l}\right)$ against $1 / T_{b}$, where adiabatic flame temperature $T_{b}$ was determined from chemical equilibrium computations. We can see that, $E / R$ of ethanol-air mixtures showed a strong dependence on the initial pressure while it did not present apparent relationship against initial 


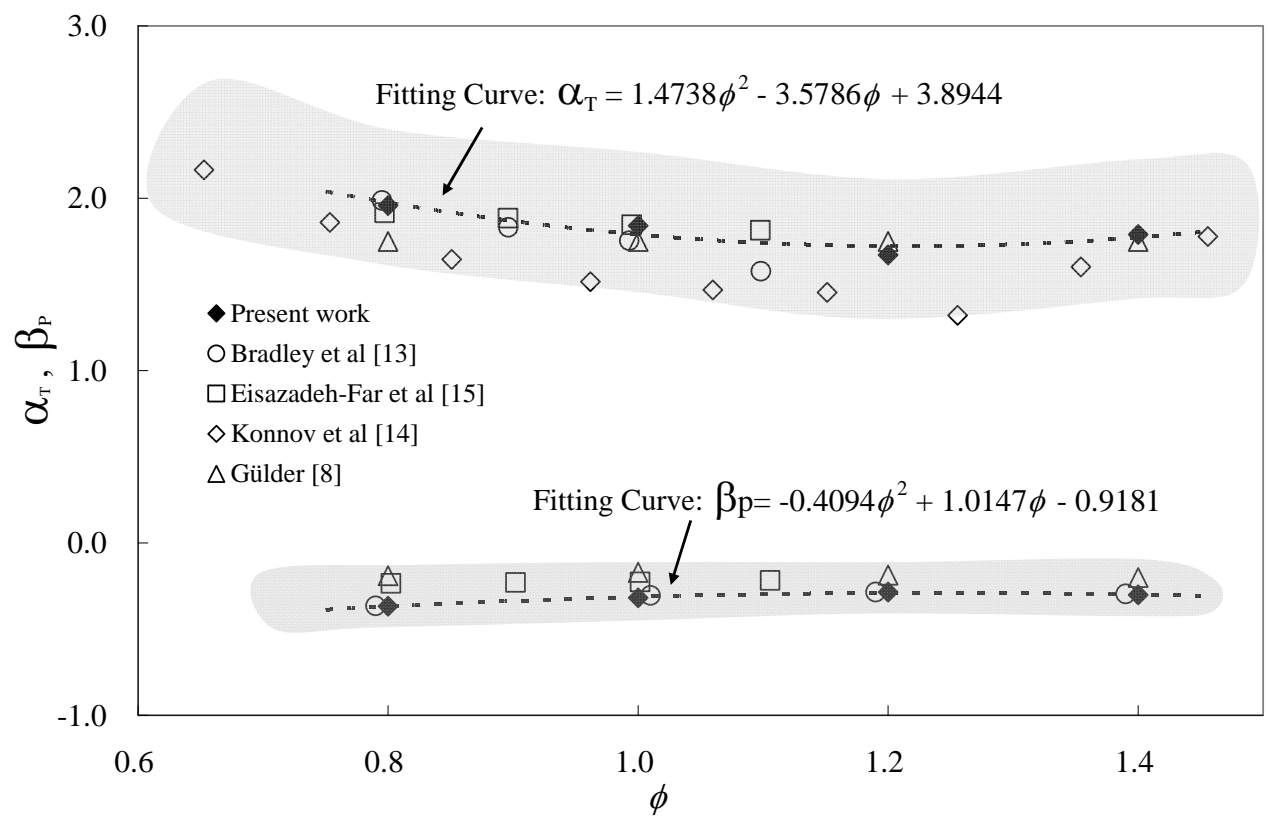

Fig. (5). Values of $\alpha_{T}$ and $\beta_{\mathrm{p}}$ exponents versus equivalence ratio of mixture, where the solid curve obtained from Eq.6, the dotted curves obtained from least-squares fitting of $\alpha_{T}$ and $\beta_{p}$ in present study. The shaded area indicates the zone of \pm 0.3 and \pm 0.15 deviations for $\alpha_{T}$ and $\beta_{\mathrm{p}}$ respectively (some symbols have been displaced slightly on the $\mathrm{x}$-axis to improve clarity).

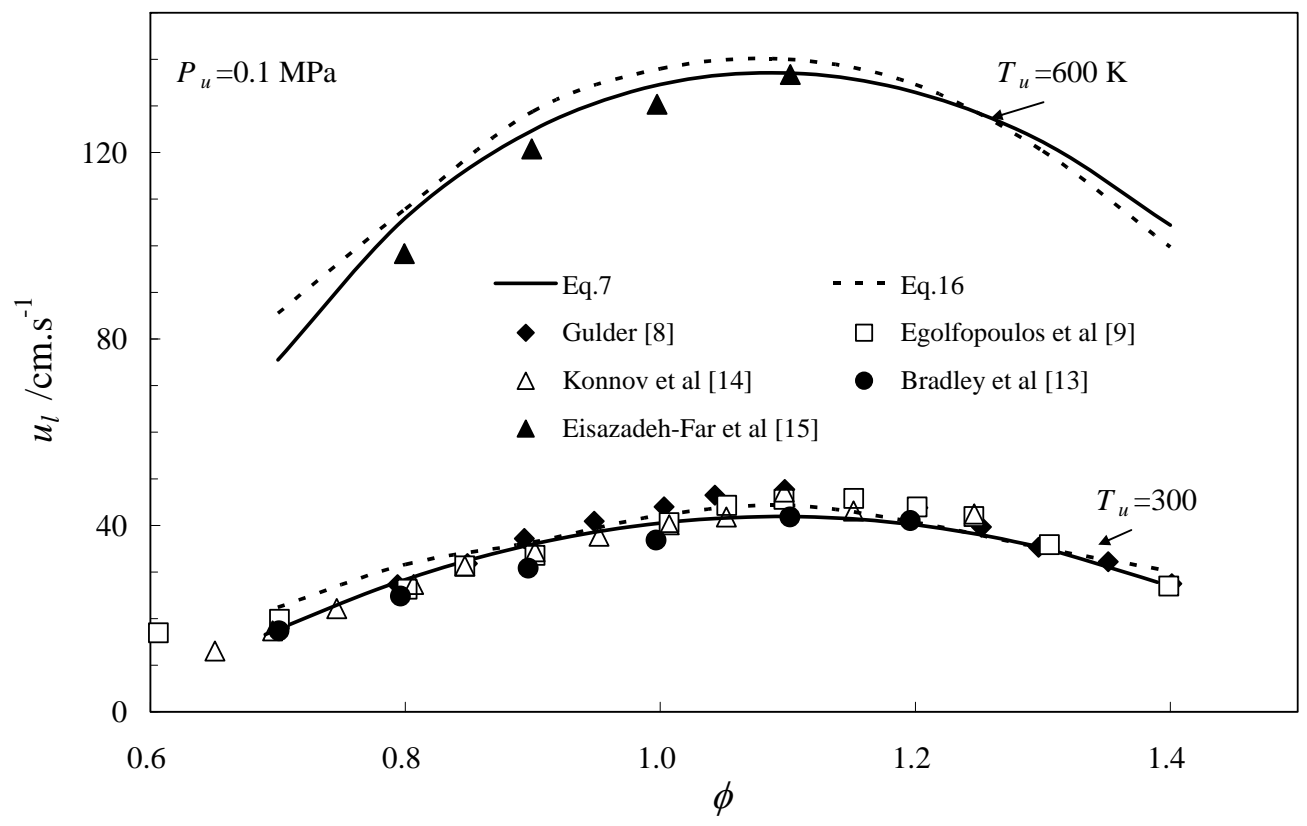

Fig. (6). Effect of initial temperature on the burning velocities for ethanol-air flames, where some symbols have been displaced slightly on the $\mathrm{x}$-axis to improve clarity.

temperature, as same as those of methane-air [5] and methanol-air [20] flames. And the pressure dependence of $E / R$ can be quantified as,

$\frac{E}{R}=985.66 P_{u}+17211$

where pressure $P_{u}$ in MPa.

Generally, from Eq.11, we could also obtain, $\ln \left(\rho_{u} u_{l}\right) /\left(\mathrm{g} . \mathrm{cm}^{2} \cdot \mathrm{s}^{-1}\right)=-\frac{E}{2 R} \frac{1}{T_{b}}+0.5 C$

where $\mathrm{C}$ is the intercept value of fitting line of Eq.13 at $1 / T_{b}=0$, and

$C=10.764 P_{u}^{0.2131}$

Then an alternative form of $u_{l}$ could be obtained as, 


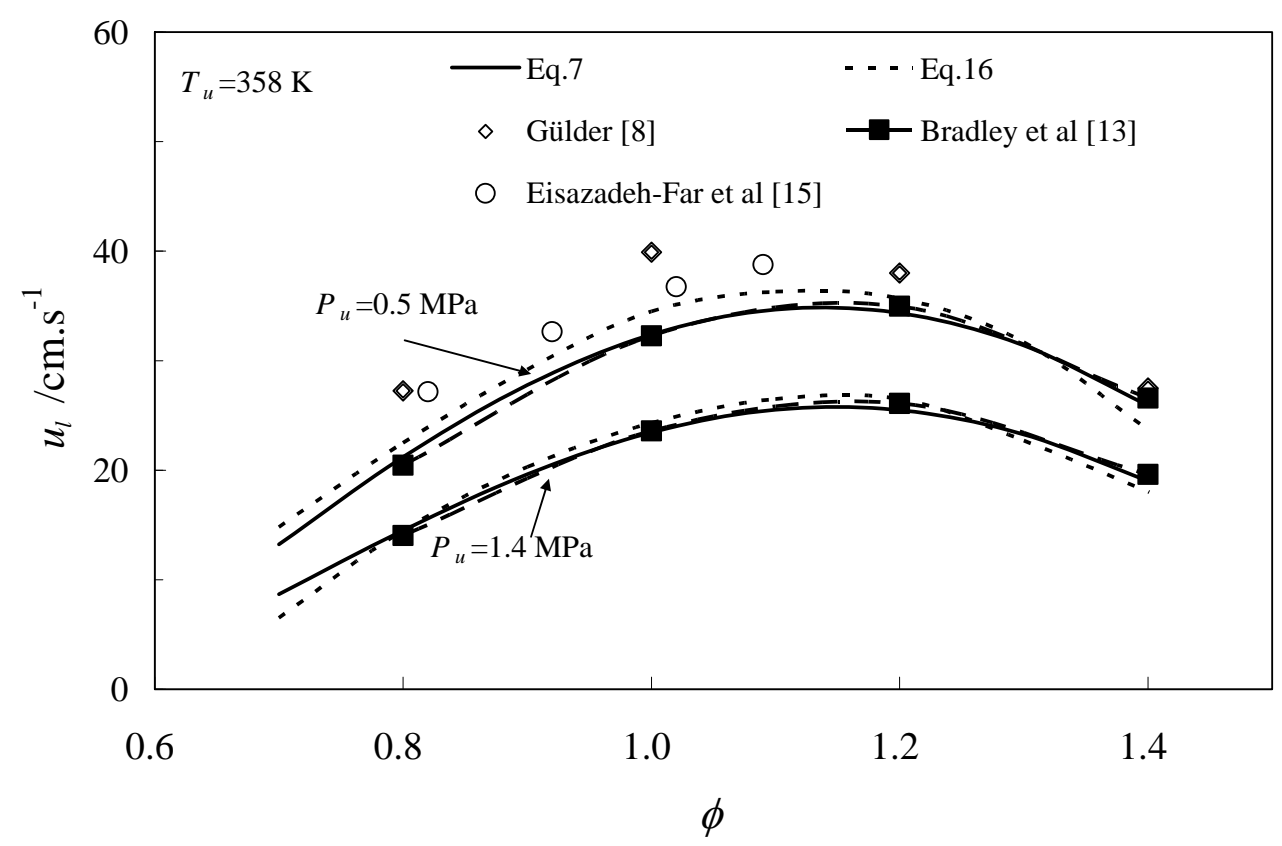

Fig. (7). Effect of pressure on the burning velocities for ethanol-air flames, where points obtained from experiments and curves from predictions, some symbols have been displaced slightly on the $\mathrm{x}$-axis to improve clarity.

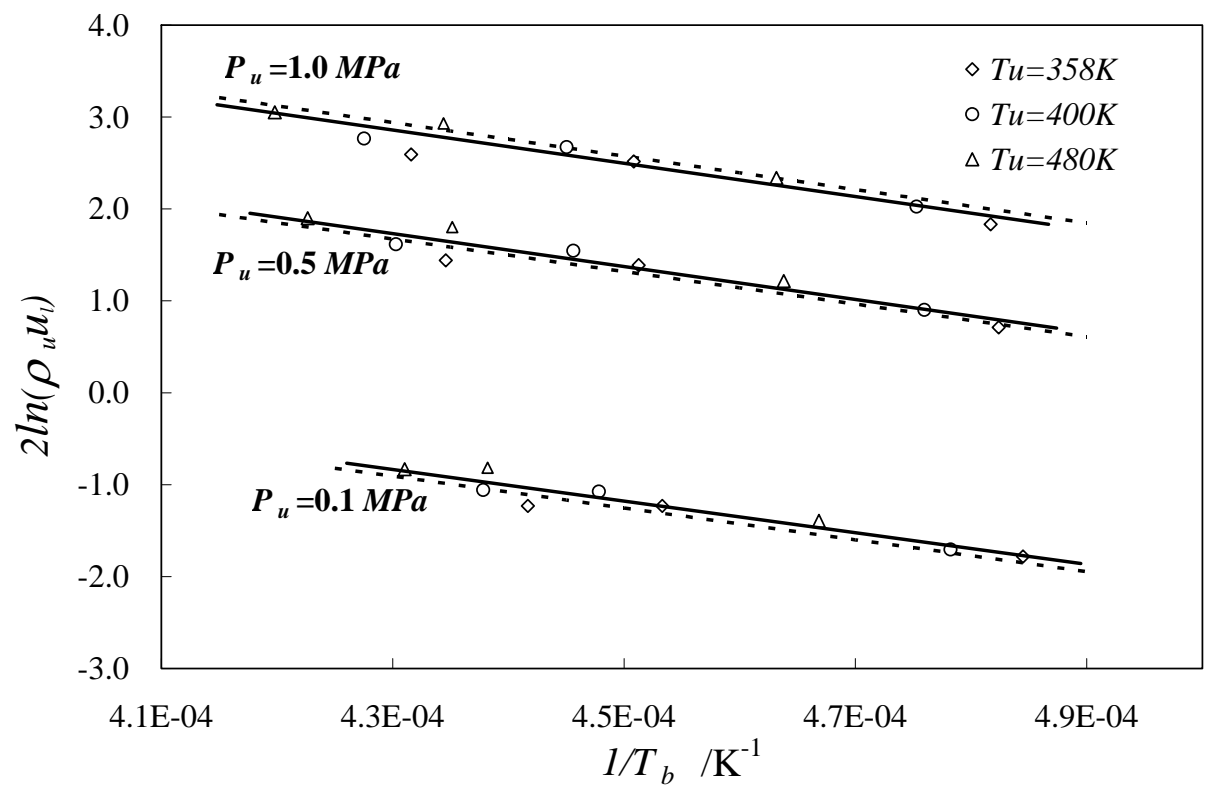

Fig. (8). Plots of $2 \ln \left(\rho_{u} u_{l}\right)$ against $1 / T_{b}$ for ethanol-air mixtures. Where solid lines are linear fits through the points obtained from Eqs.7, and dashed lines denote burning mass flux correlation of Eq.16, and some symbols have been displaced slightly on the $\mathrm{x}$-axis to improve clarity.

$u_{l} /\left(c m \cdot s^{-1}\right)=\exp \left(-\frac{E}{2 R} \frac{1}{T_{b}}\right) \frac{\exp (0.5 C)}{\rho_{u} /\left(g \cdot c m^{-3}\right)}$

The calculated laminar burning velocities of Eq.16 have been plotted in Figs. (6) and (7) with dashed curves as well, to give its validation. We note that, no apparent discrepancy appeared in the comparison with experiments as well as with predictions of Eq.7.

The Zel'dovich number, Ze, is another important parameter for planar laminar flames. Theoretical analyses have indicated that it can be determined from the active flame temperature [18].

$$
Z e=\frac{E}{2 R T_{b}^{2}}\left(T_{b}-T_{u}\right)
$$

As we know, Ze is also a parameter to describe the sensitivity of chemical reactions to the variation of the maximum flame temperature and its reciprocal is strongly related to an effective dimensionless width of the reaction zone [21]. 


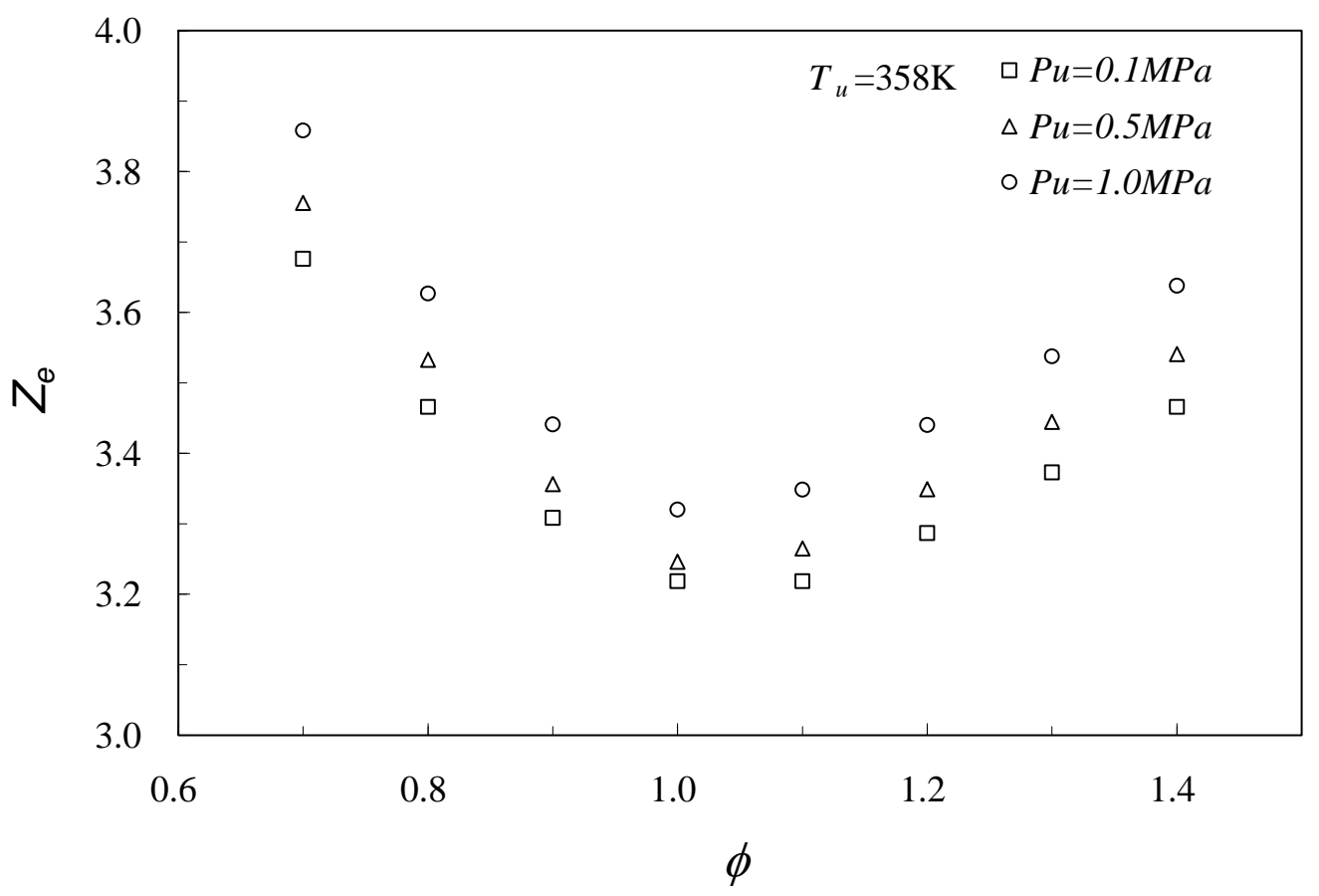

Fig. (9). Variations of $Z_{e}$ with the equivalence ratio for ethanol-air flames at different pressure.

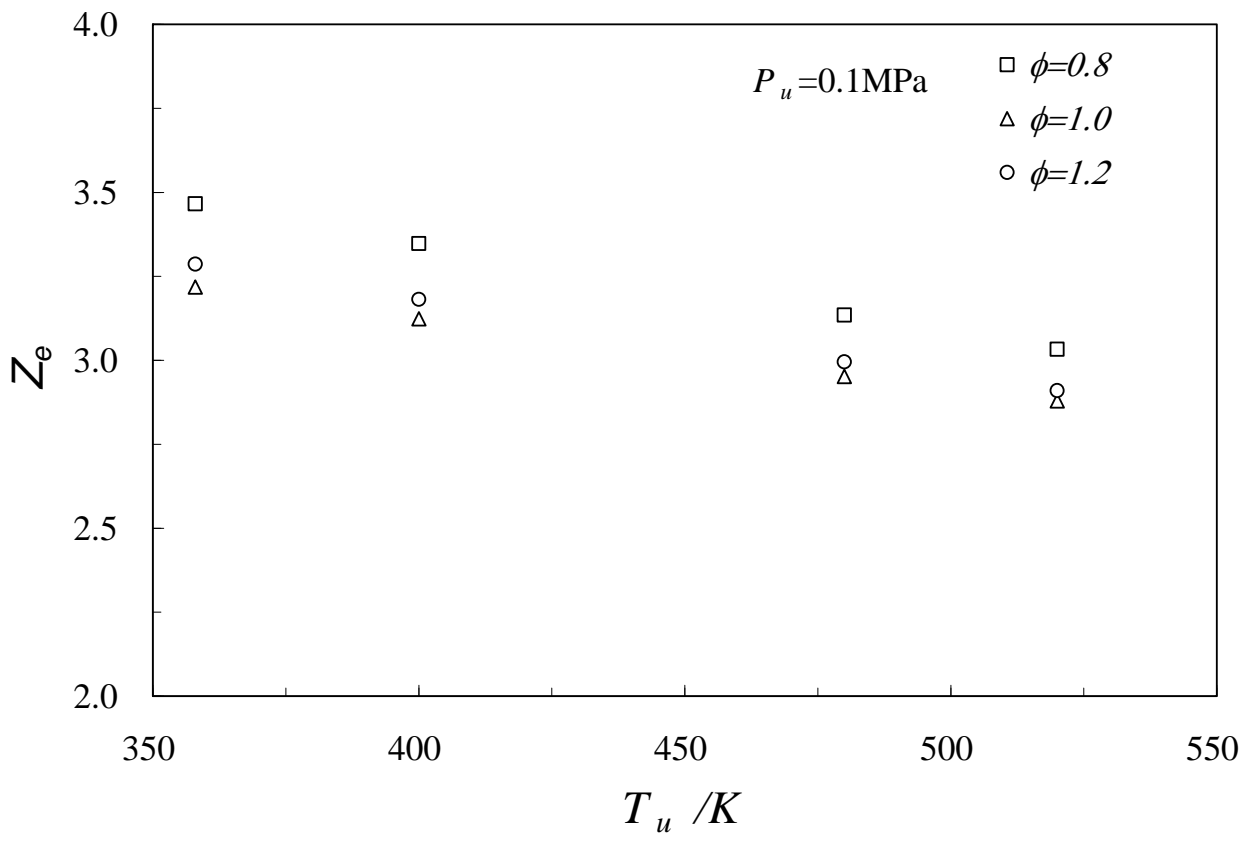

Fig. (10). Variations of $Z_{e}$ with the preheated temperature for ethanol-air flames.

Shown in Figs. (9) and (10) were the variations of $\mathrm{Ze}$ against the equivalence ratio for ethanol-air mixtures at different temperatures and pressures. As we can see, $Z e$ shows apparent dependencies on mixture equivalence ratio, temperature and pressure. Generally, the increase in pressure results in slight increase of $Z e$, because of the increased inner flame temperature $T^{0}$ [21]. And $Z e$ decreases with the increase of initial temperature slightly, owing to a decreasing ratio of $T_{b}$ to $T_{u}$. Additionally, $Z e$ attains its minimum at near-stoichiometric condition, as the peak value of flame temperature $T_{b}$ occurs herein.

\section{CONCLUSIONS}

In this paper, we conducted the experimental measurements for spherically expanding laminar flames of ethanol mixtures in air, from initial temperatures of $358 \mathrm{~K}$ to $500 \mathrm{~K}$, pressure of 0.1 to $0.2 \mathrm{MPa}$ and equivalence ratio of 0.7 to 1.4 , in a constant volume combustion bomb. The laminar 
burning velocities were estimated using the spherically expanding flame method, and comprehensive comparisons and analyses were implemented within the present measurements and literature data, to deduce the temperature and pressure dependencies of laminar propagation characteristics. The major conclusions were as follows:

1. The present measurement showed comparable laminar burning velocities against the literature data for ethanolair mixture, and an improved correlation has been proposed as $u_{l 0}=-175.02 \phi^{2}+391.1 \phi-162.5$ at $358 \mathrm{~K}$ and $0.1 \mathrm{MPa}$.

2. By means of referencing literature data, a comprehensive analysis has been made to investigate the dependencies of the propagating characteristics of premixed ethanol flames in air, on initial temperature, pressure and equivalence ratio. An empirical formula in the function form of $u_{l}=u_{l o}\left(T_{u} / T_{u 0}\right)^{\alpha_{T}}\left(P_{u} / P_{u 0}\right)^{\beta_{T}}$ was obtained, and the pressure and temperature dependence exponents of $\alpha_{\mathrm{T}}$ or $\beta_{\mathrm{p}}$ were formulized as functions of mixture equivalence ratio. These empirical expressions have been validated over much wider mixture conditions than all previous versions, in which temperature ranged from $300 \mathrm{~K}$ to $600 \mathrm{~K}$, pressure from 0.1 up to 1.4 MPa and equivalence ratio from 0.7 to 1.4 .

3. The expressions for mass burning flux, global activation temperature, and Zel'dovich numbers have been deduced on the basis of above power law formulas. And the pressure, temperature and equivalence ratio dependencies of active flame temperature and Zel'dovich numbers were studied. The global activation temperature of ethanol-air mixtures presents a strong dependence on the initial pressure, but weak relationship against initial temperature. Zel'dovich numbers increase with the increase of pressure and decreases with the increase of initial temperature.

\section{ACKNOWLEDGEMENTS}

This study is supported by National Natural Science Foundation of China (50706058, 51076167), and Open Fund from Key Laboratory of Low-grade Energy Utilization Technologies and Systems of Ministry of Education (LEUST201002).

\section{REFERENCES}

[1] J. R. Moreira, and J. Goldemberg, "The alcohol program”, Energy Policy, vol.27. pp. 229-245, 1999.

[2] V. Thomas and A. Kwong, "Ethanol as a lead replacement: phasing out leaded gasoline in Africa”, Energy Policy, vol. 29, pp. 11331143, 2001
[3] A. Konnov and I.V. Dyakov, "Measurement of propagation speeds in adiabatic cellular premixed flames of $\mathrm{CH} 4+\mathrm{O} 2+\mathrm{CO} 2$ ", Exp. Therm. Fluid Sci., vol. 29, pp. 901-907, 2005.

[4] X. J. Gu, M. Z. Haq, M. Lawes and R. Woolley, "Laminar burning velocity and Markstein lengths of methane-air mixtures”, Combustion Flame, vol. 121, pp. 41-58, 2000.

[5] X. Qin, K. Hideaki and N. Takashi, "Laminar burning velocity of hydrogen-air premixed flames at elevated pressure”, Exp. Therm. Fluid. Sci., vol. 21, pp.58-63, 2000.

[6] D. Bradley, R. A. Hicks, M. Lawes, C. G. W. Sheppard and R. Woolley, "The measurement of laminar burning velocities and markstein numbers for iso-octane-air and iso-octane-n-heptane-air mixtures at elevated temperatures and pressures in an explosion bomb”, Combustion Flame, vol. 115, 126-144. 1998.

[7] X. L. Gu, Q. Q. Li, Z. H. Huang and N. Zhang, "Measurement of laminar flame speeds and flame stability analysis of tert-butanolair mixtures at elevated pressures", Energy Conversion Manage., vol. 52(10), pp. 3137-3146, 2011.

[8] O. L. Gülder, "Laminar burning velocities of methanol, ethanol and isooctane-air mixtures”. Proc. Combustion Inst., vol. 19 no. 1, pp. 275-281, 1982.

[9] F. N. Egolfopoulos, D. X. Du and C. K. Law, “A study on ethanol oxidation kinetics in laminar premixed flames, flow reactors and shock tubes”, Proc. Combustion Inst., vol. 24 no. 1, pp. 833-841, 1992.

[10] T. Holley, Y. Dong, M. G. Andac and F. N. Egolfopoulos, "Extinction of Premixed Flames of Practical Liquid Fuels: Experiments and Simulations”, Combustion Flame, vol. 144 3, pp. 448-460, 2006.

[11] J. T. Farrell, R. J. Johnston and I. P. Androulakis, "Molecular Structure Effects on Laminar Burning Velocities at Elevated Temperature and Pressure”, In: SAE Paper, 2004-01-2936, 2004.

[12] S. Y. Liao, D. M. Jiang, Z. H. Huang, K. Zeng and Q. Cheng, "Determination of the laminar burning velocities for mixtures of ethanol and air at elevated temperatures", Appl. Therm. Eng., vol. 27 no. 2-3, pp. 374-380, 2007.

[13] D. Bradley, M. Lawes and M. S. Mansour, "Explosion bomb measurements of ethanol-air laminar gaseous flame characteristics at pressures up to 1.4 MPa”. Combustion Flame, vol.156, pp.14621470, 2009.

[14] A. Konnov, R. J. Meuwissen and L. P. H. de Goey, "The temperature dependence of the laminar burning velocity of ethanol flames". Proc. Combustion Inst., vol. 33(1), pp.1011-1019, 2011.

[15] K. Eisazadeh-Far, A. Moghavedas, J. Al-Mulki and H. Metghalchi, "Laminar burning speeds of ethanol/air/diluent mixtures", Proc. Combustion Inst., vol. 33(1), pp.1021-1027, 2011.

[16] J. H. Wang, Z. H. Huang, H. Y. Miao, X. B. Wang and D. M. Jiang, "Characteristics of direct injection combustion fuelled by natural gas-hydrogen mixtures using a constant volume vessel", Int. J. Hydrogen Energy, vol. 33(7), pp. 1947-1956, 2008.

[17] C. Mandilas, M. P. Ormsby, C. G. W. Sheppard and R. Woolley, "Effects of hydrogen addition on laminar and turbulent premixed methane and iso-octane-air flames", Proc. Combustion Inst., vol. 31 (2), pp. 1443-1450, 2007.

[18] Y. B. Zel'dovich, G. I. Barenblatt, V. B. Librovich and GM Makhviladze, The Mathematical Theory of Combustion and Explosions. Consultants Bureau: New York and London, 1985.

[19] N. Peters and F. A. Williams, "The asymptotic structure of stoichiometric methane---air flames”, Combustion Flame, vol. 68, pp. 185-207, 1987.

[20] S. Y. Liao, D. M. Jiang, Z. H. Huang and K. Zeng, "Characterization of laminar premixed methanol-air flames", Fuel, vol. 85(1011), pp.1346-1353, 2006.

[21] J. Go"ttgens, F. Mauss and N. Peters, "Analytic approximations of burning velocities and flame thicknesses of lean hydrogen, methane, ethylene, ethane, acetylene, and propane flames”, Proc. Combustion Inst., vol. 24(1), pp.129-135, 1992. 